elisen: $978.1-1.68108 .225 .7$
ISBN: $978-1.68108-226-4$

\section{MAN AND SHELLS}

Molluscs in the History

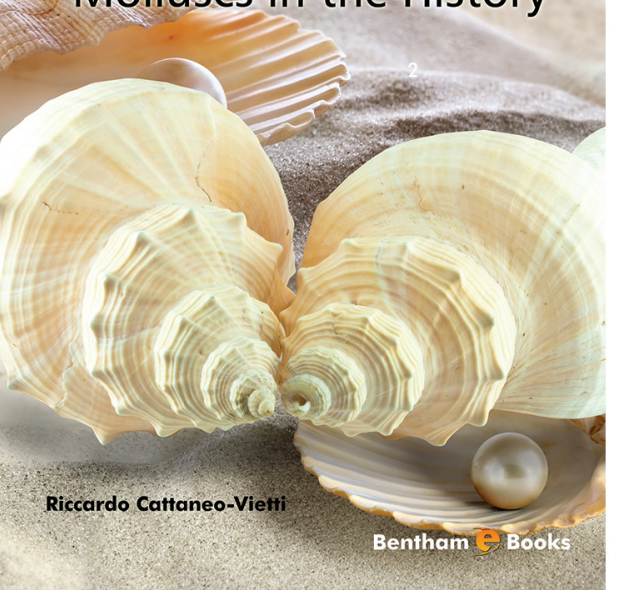

E-book Price

US\$ 171.00

Print-on-Demand

US\$ 127.00

Author:

Institutional E-Book Price

US\$ 684.00

\title{
Riccardo Cattaneo-Vietti
}

Italy

elSBN: $978-1-68108-225-7$

\section{MAN and SHELLS: Molluses in the History}

\section{http://ehooks.henthamseience.Com/hook/9781681082257/}

\section{About the eBook}

Man and Shells is a treatise on molluscs in our natural history. Readers will traverse through the journey by demonstrating how these organisms have accompanied humans in arts and culture, in ancient religions, the myths that surround them, their role in commerce as in dyeing and as currency as well as in aquaculture and fishing, and much more. Man and Shells helps us to appreciate these creatures that continue to have an important yet little known place in the cultural evolution of man through the age.

\section{Contents}

- Not only Shells

- Magic, Mythology, and Religion

- The Trumpet Conchs

- In art

- Handicrafts and the Kitsch

- Shells as Currency

- Pearls and mother-of-pearl

Dyes, Tissues, and Materials

- Madly in Love with Shells

- Food for Man: Cooked and Raw

- Farming Molluscs

- Import and Export: Successes and Flops

- Dangerous Molluscs? Myths and Reality

Threatened Species

- Serving Science

- References

For Advertising Inquiries: Contact: marketing@benthamscience.org 